\title{
A Safe, Effective, and Alternative Technique for Fascial Port Site Closure
}

\author{
Ali Akdemir, MD, Sevtap Seyfettinoglu, MD, Levent Akman, MD, Fatih Sendag, MD, \\ Mehmet Kemal Oztekin, MD \\ Department of Obstetrics and Gynecology, Ege University School of Medicine, Izmir, Turkey (all authors).
}

\begin{abstract}
Background and Objectives: Fascial closure of the $10-\mathrm{mm}$ and $12-\mathrm{mm}$ port sites is mostly recommended to avoid port site incisional herniation. However, it is often difficult and time-consuming. The aim of this study is to describe a novel technique for fascial closure of laparoscopic port sites.

Methods: The fascial closure was performed using straight needle and standard surgical instruments under the laparoscopic visualization in 100 patients. The time duration of the closure, intraoperative and postoperative complications, and patient characteristics were recorded. All patients were examined at postoperative third and sixth months.
\end{abstract}

Results: Intraoperative or postoperative complications were not observed. The mean time for fascial closure was 90 seconds. No port site hernia was encountered at the third month and sixth month postoperative examinations.

Discussion: The present technique is safe, effective, easy, and does not require any special instruments. Our technique should be kept in mind during fascial closure of the laparoscopic port sites.

Key Words: Fascial closure, Laparoscopy, Port site herniation.

Citation Akdemir A, Seyfettinoglu S, Akman L, Sendag F, Kemal Oztekin M. A safe, effective, and alternative technique

for fascial port site closure. CRSLS e2014.00023. DOI: 10.4293/CRSLS.2014.00023.

Copyright $\odot 2014$ SLS This is an open-access article distributed under the terms of the Creative Commons Attribution-Noncommercial-ShareAlike 3.0 Unported license, which permits unrestricted noncommercial use, distribution, and reproduction in any medium, provided the original author and source are credited.

Address correspondence to: Ali Akdemir, Ege University School of Medicine, Department of Obstetrics and Gynecology, 35100, Bornova, Izmir, Turkey. Telephone +902323901700, Fax: +902323430711, E-mail: md.aliakdemir@gmail.com

\section{INTRODUCTION}

Terminology of port site incisional hernia has been come into surgical practice after the first report by Fear. ${ }^{1}$ The port site incisional hernia is defined as the development of a hernia at the laparoscopic cannula insertion site. ${ }^{1,2}$ The incidence of the port site hernias has been reported between $0.2 \%$ and $3.1 \% .^{3}$ Although it is rare, it is a serious complication because most of the port site hernias require additional surgery. ${ }^{3}$ Trocar size, location, trocar type, trocar manipulation, closure technique, and preexisting fascial defects have been the considered factors that may play a role in the development of port site hernias.3,4 Among the related factors, closure of the fascial defect at the trocar site is one of the important, technique-dependent factors. It has been recommended that the fascial closure is necessary when large trocars are used or after dilation of a port site for specimen removal. In the literature, there are numerous types of surgical techniques and commercial apparatus for fascial closure. ${ }^{5-7}$ Despite requiring the closure of fascial defects after laparoscopy, the fascial closure at the port sites may be difficult and frequently blind suturing is needed. ${ }^{6,7}$ Blind suturing especially carries the probable risks including incomplete suturing, injury to intra-abdominal organs, and larger skin incisions. ${ }^{7}$ Therefore, we describe our technique for port site fascial closure.

\section{MATERIALS AND METHODS}

At the end of the laparoscopic surgery, before releasing the pneumoperitoneum, a 10-mm telescope is switched to $5-\mathrm{mm}$ telescope. The $5-\mathrm{mm}$ telescope is introduced into the abdominal cavity for visualization of $10-\mathrm{mm}$ and 12 -mm port sites. Next, the $10-\mathrm{mm}$ or $12-\mathrm{mm}$ port is pulled out and the skin incision is covered with the index finger of the nondominant hand of the surgeon. 
The closure technique is as follows (Figure 1). (Whole surgical steps are performed under the view of $5-\mathrm{mm}$ laparoscopic telescope.)

1. A straight needle is introduced into the abdominal cavity through the port incision and puncturing 1 edge of the fascia and peritoneum (not skin) with the guidance of the surgeons' index finger.

2. The needle is then grasped with the laparoscopic instrument from inside the abdominal cavity to pull the needle completely into the abdomen.

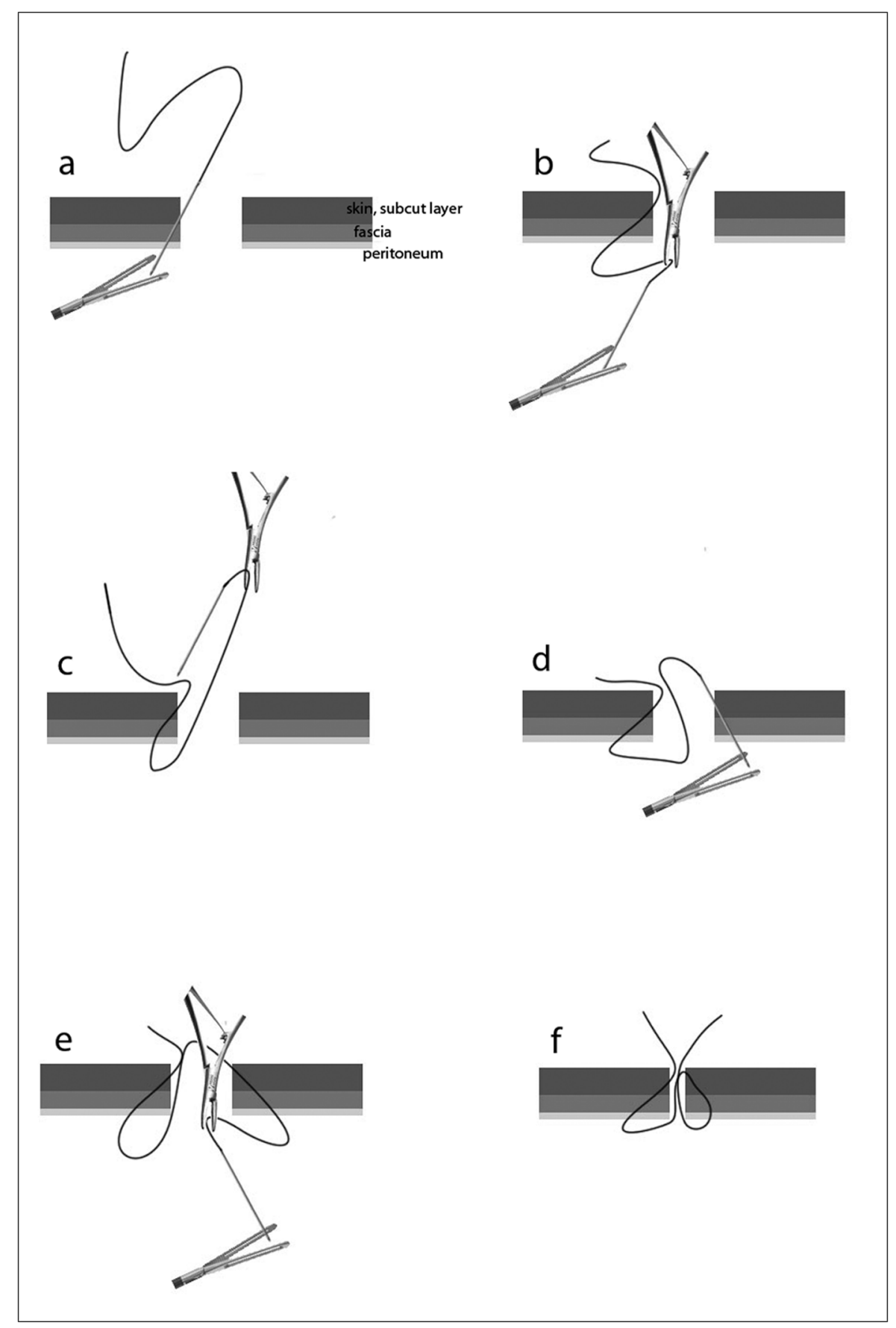

Figure 1. Step-by-step demonstration of fascial closure. 
3. Subsequently, a needle holder is introduced into the abdominal cavity through the port incision and the needle is grasped and pulled out the abdominal cavity.

4. The first 3 technical steps are repeated for the other edge of the fascia and peritoneum.

5. Finally, 2 ends of the suture are tied outside the abdominal cavity inside the skin incision.

This technique was performed in 100 consecutive operative laparoscopic operations. Forty-five of them were laparoscopic ovarian endometrioma surgeries, 34 of them were laparoscopic myomectomies, and 21 of them were laparoscopic surgeries for ovarian dermoid cyst. In our clinical practice, during the operative laparoscopic procedures, the operating surgeon and assisting surgeon always stand on the left and right sides of the patient, respectively. Four trocars are placed for operative laparoscopic procedures: 1 10-mm trocar at umbilicus, $25-\mathrm{mm}$ trocars at the lower abdominal quadrants, and $15-\mathrm{mm}$ trocar at the left upper quadrant. At the end of the operative laparoscopic procedure, the left lower quadrant 5-mm trocar incision is enlarged to $10 \mathrm{~mm}$ for specimen extraction or myoma morcellation. Thus, fascial closure with technique just described was used for the left lower abdominal and umbilical port sites. The study was approved by the University Ethics Committee (13-1/5.May.2013). The surgical technique and the study was explained to all patients, and informed consent was obtained from all patients.

\section{RESULTS}

Fascial incisions of 200 port sites were successfully closed with this technique in 100 operative laparoscopic procedures without any complications. The median time for fascial closure of the port site was 90 seconds (range 60-200 seconds). The median age of the women was 32 years (range 18-61 years), and median body mass index was $26.5 \mathrm{~kg} / \mathrm{m}^{2}$ (range $21-36 \mathrm{~kg} / \mathrm{m}^{2}$ ). No complications occurred during the port site closure. No port site hernia was encountered at third month and sixth month postoperative examinations. Postoperative examination was performed with clinical examination and ultrasonography. Ultrasonography was used when a port site hernia was suspected with clinical examination.

\section{DISCUSSION}

The incidence of port site hernias is $0.23 \%$ and $1.9 \%$ for $10-\mathrm{mm}$ and $12-\mathrm{mm}$ ports, respectively. ${ }^{6}$ The specimen removal through the port incisions and obesity can increase the incidence. Besides, infection, premature suture disruption or failure to approximate the fascial wound edges properly may facilitate the port site herniation. ${ }^{5}$ Thus, appropriate fascial closure of the $10-\mathrm{mm}$ and $12-\mathrm{mm}$ port sites is mostly recommended to avoid this complication.

Numerous different methods for port site closure have been described in the literature. ${ }^{5}$ Shaher ${ }^{5}$ has classified the port site closure methods into 3 main groups: (1) methods that require assistance from inside the abdomen with 2 additional ports ( 1 for the laparoscope, 1 for the grasper), (2) methods that require extracorporeal assistance and 1 additional port, and (3) methods that do not require additional ports. Most of the methods described in the literature need special devices and this incurs additional costs. Besides, some investigators found the use of special devices time-consuming and a disadvantage. 6,7

The method described in the present study requires 2 additional ports ( 1 for laparoscope and 1 for grasper) and needs visualization from inside the abdominal cavity. Thus, it can be listed in the first group of Shaher's classification. Because our method does not require special device, it does not cost much.

Based on our experience, the gas leakage from the port incision during the closure is among the important obstacles for the present method. Because the tip of the straight needle enters into the abdominal cavity in a perpendicular angel, adequate pneumoperitoneum should be established to prevent the intra-abdominal organ injuries. For this purpose, the surgeon should cover the incision with the index finger of the nondominant hand to prevent the gas leakage; this maintains adequate pneumoperitoneum. Besides, by using the nondominant index finger, the straight needle can easily be guided for puncturing the fascial edge of the wound. In this way, the dominant hand of the surgeon can facilitate the manipulation of the needle during the closure.

Williams et $\mathrm{al}^{8}$ described an alternative technique for port site closure. They used hemostatic tonsil forceps to deliver a suture into the abdominal cavity via a puncture through the fascia under visual guidance. They then performed a similar puncture with the same instrument on the opposite site of the fascial defect under direct vision to grasp the suture. In our opinion, the resistance of the fascia against the tonsil forceps or other open surgical instruments during the puncturing for suture delivery could cause uncontrolled abdominal entrance. This could cause intra-abdominal injuries. Related to this, Williams et $\mathrm{al}^{8}$ described their technique in laparoscopic hand-assisted radical nephrectomy procedure. Thus, they described the use of surgeon's hand from inside the abdominal cavity to prevent the uncontrolled entrance of the tonsil forceps. Sim- 
ilarly, the GORE TEX (W. L. Gore \& Associates, Flagstaff, Arizona) suture passer has the same principles, and has same probable risk of uncontrolled abdominal entrance. ${ }^{9}$ Based on our experience, uncontrolled abdominal entrance can be prevented with using a surgical needle. Becuase the tip of the needle is thinner and sharper than the instruments that were just mentioned, puncturing the fascia and peritoneum can easily be achieved. Therefore, laparoscopic visualization of the procedure also prevents the intra-abdominal injuries.

\section{CONCLUSIONS}

Results of the present study showed that the method for port site closure with our technique took approximately 2 minutes. Therefore, the method should be considered time-saving. Because we did not encounter any complications during the closure and no port site hernia was detected at the postoperative follow-up, our method should be considered feasible and safe.

\section{References}

1. Fear RE. Laparoscopy: a valuable aid in gynecologic diagnosis. Obstet Gynecol. 1968;31(3):297-309.
2. Crist DW, Gadacz TR. Complications of laparoscopic surgery. Surg Clin North Am. 1993;73(2):265-289.

3. Yamamoto M, Minikel L, Zaritsky E. Laparoscopic 5-mm trocar site herniation and literature review. JSLS. 2011;15(1):122126.

4. Tonouchi H, Ohmori Y, Kobayashi M, Kusunoki M. Trocar site hernia. Arch Surg. 2004;139(11):1248-1256.

5. Shaher Z. Port closure techniques. Surg Endosc. 2007;21(8): 1264-1274.

6. Di Lorenzo N, Coscarella G, Lirosi F, Gaspari A. Portsite closure: a new problem, an old device. JSLS. 2002;6: $181-183$

7. Botea F, Torzilli G, Sarbu V. A simple, effective technique for port-site closure after laparoscopy. JSLS. 2011;15:77-80.

8. Williams SB, Greenberger ML, Pearce WF, Tertzakian GM. Alternative technique for laparoscopic port-site closure. J Endourol. 2012;26:311-312.

9. Chapman WH 3rd. Trocar site closure: a new and easy technique. J Laparoendosc Adv Surg Tech. 1999;9(6):499-502. 